\title{
CUSTOMER-DEFINED QUALITY OF FOOD: AN EMPIRCAL INVESTIGATION BASED ON KANO ANALYTICAL METHODS FOR MILK POWDER
}

\author{
W A K I Lakni ${ }^{1}$ and U K Jayasinghe-Mudalige ${ }^{1}$
}

\begin{abstract}
Using the Kano Analytical Methods [KAM] (Kano et al., 1984), this study examined empirically the consumer satisfaction towards 18 food quality attributes defined in the Caswell's classification on customer-defined food quality for the special case of milk powder products. A two-stage research program (i.e. to identify the different forms of attributes and to classify which using the KAM) was carried out to collect data from consumers in a supermarket setting in the Gampaha district from May to June 2008. The results show that consumers judge the 18 attributes as: (a) 4 "One-dimensional" (calorie content, compositional integrity, labeling, past purchase experiences); (b) 7 "Attractive" (size, fat and cholesterol content, taste, appearance, package material, brand name, advertising); (c) 5 "Indifferent" (size, place of origin, price, smell, food additives \& preservatives), and $(d) 2$ "Must-be" (no pathogens, certification). The results are vital for food marketers to adjust the quality of their products to respond effectively to the consumer demands for both intrinsic and extrinsic food quality attributes.
\end{abstract}

Key words: Kano Analytical Methods, milk powder, food quality, consumer.

\section{INTRODUCTION}

\section{Consumer Concerns on Food Quality}

Consumer concerns about the quality of food products has become one of the major and increasing preoccupations of the food supply system in almost every country in the recent past. This has been triggered by a number of factors, including the occurrences of millions of cases of human illness and thousands of deaths worldwide every year cause by food-borne microbial pathogens and other agents, a number of recent food scandals and crises resulting from animal diseases (e.g. Foot \& Mouth Disease), an increasing public concern about the health effects of certain foodstuffs (e.g. Genetically Modified Organisms) and new food processing technologies (e.g. hormone treated meat), certain environmental catastrophes (e.g. Dioxin), and adverse health affects of some drugs and agro-chemicals (e.g. DDT, Aflatoxins).
Besides these, the liberalization and globalization of world trade, thus, various groups of agricultural producers and processors as well as governments utilize the increased importance of food safety as a weapon of protection of their domestic market and/or the position of the market to contribute towards increased concerns of consumers to a greater extent (Buzby et al, 2001; Henson and Caswell, 1999).

As a result, in the current world context, an ever-growing number of consumers require more information on products they consume. In response to that, governments and respective food processing industries in almost all developed and most of the developing countries are intensifying their efforts to improve food quality. Although relatively little Sri Lankan research has been reported to date on the economics behind assurance of food safety and quality, evidence from public polls of attitudes towards food safety from several other countries (Buzby, 2003; Spriggs and

\footnotetext{
${ }^{1}$ Dept. of Agribusiness Management, Faculty of Agriculture \& Plantation Management, Wayamba University of Sri Lanka, Sri Lanka
} 
Isaac, 2001) indicates that consumers, in general, have high expectations that both producers and public policy ensure that all food that is sold will be safe to consume.

Therefore, the challenge lies in designing a system that assures consumers of a safe and quality food supply while avoiding draconian measures which hamper the competitiveness of the food production and processing industries by cutting back the incentives for producers, with little marginal benefit in improved safety (Jayasinghe-Mudalige and Henson, 2006). In this context, it is essential to have a clearer answer to the economic problem of what "attribute/s of food quality" the consumers, in general, pay the highest attention in the market as they purchase food at the retail level, and in turn, whether can we rank and order these attributes in such a way to reflect the relative importance of each attribute to the potential consumers. Identifying so is vital for food marketers and also to the governments to improve and extend the functioning of food markets in terms of these attributes that would, in turn, eliminate the inconsistencies and conflicts that might lead for food quality related failures.

\section{Customer-defined Quality of Food}

The quality management literature explores several attributes of product quality from various standpoints, and as a result, there is no definitive list of all attributes of quality reported. Garvin (1987), for example identified eight dimensions of product quality, including: (1) performance; (2) features; (3) reliability; (4) conformance; (5) durability; (6) serviceability; (7) aesthetics, and (8) perceptions. Brown (1994) specifies a number of indicators to measure quality, including: (1) the product service quality; (2) operational quality; (3) financial quality; (4) public responsibility, and (5) employee / customer satisfaction. Each of above indicators can be evaluated by means of a subset of other variables, for example, employee satisfaction is a function of turnover, request for transfer, complaints and absenteeism. In view of the fact that quality itself is "multidimensional" in nature, the importance of such characteristics can be varied across circumstances and among customers. The national level regulation aiming product quality in many developed and developing countries, as a result, takes on many dimensions or regimes.

The attributes of food quality have, however, not been well specified in the food economics literature until recently. According to Espejel et al. (2007), quality of a food product can be evaluated using two main different perspectives, namely (1) the objective quality, and (2) the perceived / subjective quality. The former refers to the technical, measurable and verifiable nature of products / servers, processes and quality control. Subjective or perceived quality refers the consumer's value judgments or perceptions of quality. According to Zhifeng (2007), food quality can be defined as an intrinsic property of food which meets a pre-standard requirement. In this way food quality can be determined by means of the properties with respect to nutrition, hygiene, organoleptic and functions of food.

Caswell (1998) and Hooker and Caswell (1998) identify five major subsets of quality attributes: (1) food safety; (2) nutrition; (3) value; (4) package, and (5) process. Among which, food safety attributes are considered the most important subset that includes food borne pathogens, heavy metals, pesticide residuals, food additives, naturally occurring toxins and veterinary residues. Nutrition attributes from the second group, includes attributes such as fat content, calories, fiber, sodium, vitamins and mineral etc. Third subset of characteristics is referred as value attributes that include 
certain characteristics that are of value to the consumer but are not directly associated with food safety or nutritional attributes, for example purity (i.e. lack of non-hazardouscontaminants), ompositional integrity(i.e. lack of economic adulteration), size, appearance, convenience of preparation and taste.

Package attributes form the fourth subset includes package materials, labeling and other information provided. The final subset consists of process attributes such as animal welfare, biotechnology, worker safety and environmental impact. However, they affirm that many quality concerns embody attributes from more than one of these subsets, for example consumer who purchases an organic product may be concerned with food safety, nutritional, and value attributes, thus justify multiple regulatory regimes and more dynamic food safety controls (Caswell et al., 2000; Caswell and Mojduszka, 1996; Caswell and Padberg, 1992).

Caswell et al. (2000) further elaborate on this aspect by indicating the quality attributes of the food product in terms of three dimensions: (1) intrinsic or extrinsic; (2) informational environment, and (3) vertical or horizontal differentiation. Intrinsic attributes are defined as quality and quality perceptions influenced by attributes that are physical aspects of a product (nutritional content) and extrinsic attributes are related to the product, but not in the physical part of the product (brand name). The major intrinsic quality attribute subsets for food products include food safety, nutrition, sensory, value and process attributes. Extrinsic can be defined from two dimensions, i.e. test / measurement indicators and cues.

Information environment is related to the information about product quality of a "search" nature (i.e. the buyer can judge quality by evaluating the product prior to purchase - e.g. color), "experience" nature (i.e. the buyer must used the product in order to evaluate the quality - e.g. taste) and "credence" nature (i.e. the buyer cannot judge product quality even after purchase and use - e.g. pesticide residues). The third category, vertical or horizontal differentiation is defined in terms of ranking of various aspects of quality by consumers, i.e. if all buyers share the same quality ranking - vertical, and buyers have different quality ranking - horizontal.

In light of these, the specific objective of this study was to identify and categorize consumer's perceived quality attributes of food from an empirical point of view. It uses the Caswell's (1998) classification as the base for defining customer-defined food quality. Considering its high relevance and ability to come up with objective measurements to assess consumer concerns about food quality, the "Kano's Analytical Methods" (KAM) cited in the Management Literature was used (Kano et al, 1984). The milk powder industry in Sri Lanka was considered as the case for empirical analysis due to various reasons, including the products from the milk powder industry is characterized by almost all these attributes of food quality, the industry is frequently subjected to issues related to food safety and quality (e.g. the Melamine case in China) and as it plays a key role in shaping the socio-economic and political economy of Sri Lanka in the recent past.

\section{MATERIALS AND METHODS}

One criticism concerning quality is that people often consider all quality attributes to be equally important, but the inability to assign relative importance will result in the creation of mediocre products. To help one better understand how customers evaluate and perceive quality attributes of a given product, Professor Kano and his coworkers (Kano et al. 1984) developed the "Theory of Attractive Quality" to overcome such 
empirical issues. It explains how the relationship between the degree of sufficiency and customer satisfaction with a quality attribute can be classified into a number of categories of perceived quality. Kano et al. (1984) suggest a perspective on quality where a quality attribute is defined in different quality categories based on the relationship between the physical fulfillment of a quality attribute on a product and the perceived satisfaction of that attribute. The relationships are not equal for all quality attributes and they change over time. The Kano's Analytical Methods (KAM) as related to this particular study along with the methods used to collect and analyze data is explored in the proceeding section.

\section{Use of KAM to Assess the Consumer Perceptions}

Given a large number of "attributes" of quality $(j=1,2,3 \ldots \mathrm{Q})$ associated with a certain food product (milk powder in this particular case), one can use the KAM to rank and order objectively the most preferred attributes of the product by a set of respondents $(i=1,2,3 \ldots \mathrm{N})$ consume that product (Berger et al., 1993). Under the KAM, the consumer perceptions with regard to quality of a food product is mainly classified into 4 categories, namely: (1) "One-dimensional" [O]; (2) "Attractive" [A]; (3) "Must-be" [M], and (4) "Indifferent" [I]. The Kano Diagram shown in Figure 1 can be used to explore these 4 categories further in which the horizontal axis illustrates the "functionality of a product" and the vertical axis specifies the "level of satisfaction of customer" (i.e. how satisfied the customer is with the given attribute).

In the Kano diagram, the line goes through the origin at 45-degree angle designates as "One-dimensional" customer requirements, i.e. if the product is more (less) functional, a consumer would be more (less) satisfied with the product. This simply says that consumer satisfaction, as shown in Figure 1, is simply proportional to the functionality of "One-dimensional" requirements. The "Attractive" curve in Figure 1 highlights that a customer is more satisfied when the product is more functional, but is not dissatisfied when the product is less functional. In other words, this is the situation where the "lack of a particular quality attribute" in the product leaves the consumer "neutral", but having more with respect to that attribute will quickly increase the consumer's level of satisfaction.

The "Must-be" curve indicates the attributes that result in dissatisfaction when it is not fulfilled. However, it must be noted that the level of satisfaction of a consumer will never rise above neutral when it is fulfilled. In the Figure 1, the "Indifference" is plotted roughly along the horizontal axis, i.e. a customer is neither satisfied nor dissatisfied whether the product is dysfunctional or fullyfunctional ${ }^{1}$.

\footnotetext{
${ }^{1}$ In addition to the 4 Kano categories specified above, most of the time, there are certain other categories too consider in the KAM, including: "Questionable" [Q] and "Reverse" [R]. If any attribute considered in the Kano analysis receives a significant number of "Questionable" scores that indicates there is confusion for consumers with the question asked to rate their preferences. On the other hand, if the majority of scores for a given attribute is "Reverse", it indicates that the respondents favor that attribute in its opposite manner as stated by the question (see below) (Berger et al., 1993).
} 
A two-stage research program was adopted to achieve the objectives of this study, including: Phase $I-$ to identify the preferable "forms" of an attribute of quality for the milk powder varieties available commonly for consumers in Sri Lanka, and Phase II - to classify those food quality attributes of milk powder (identified in Phase I) into the Kano categories specified.

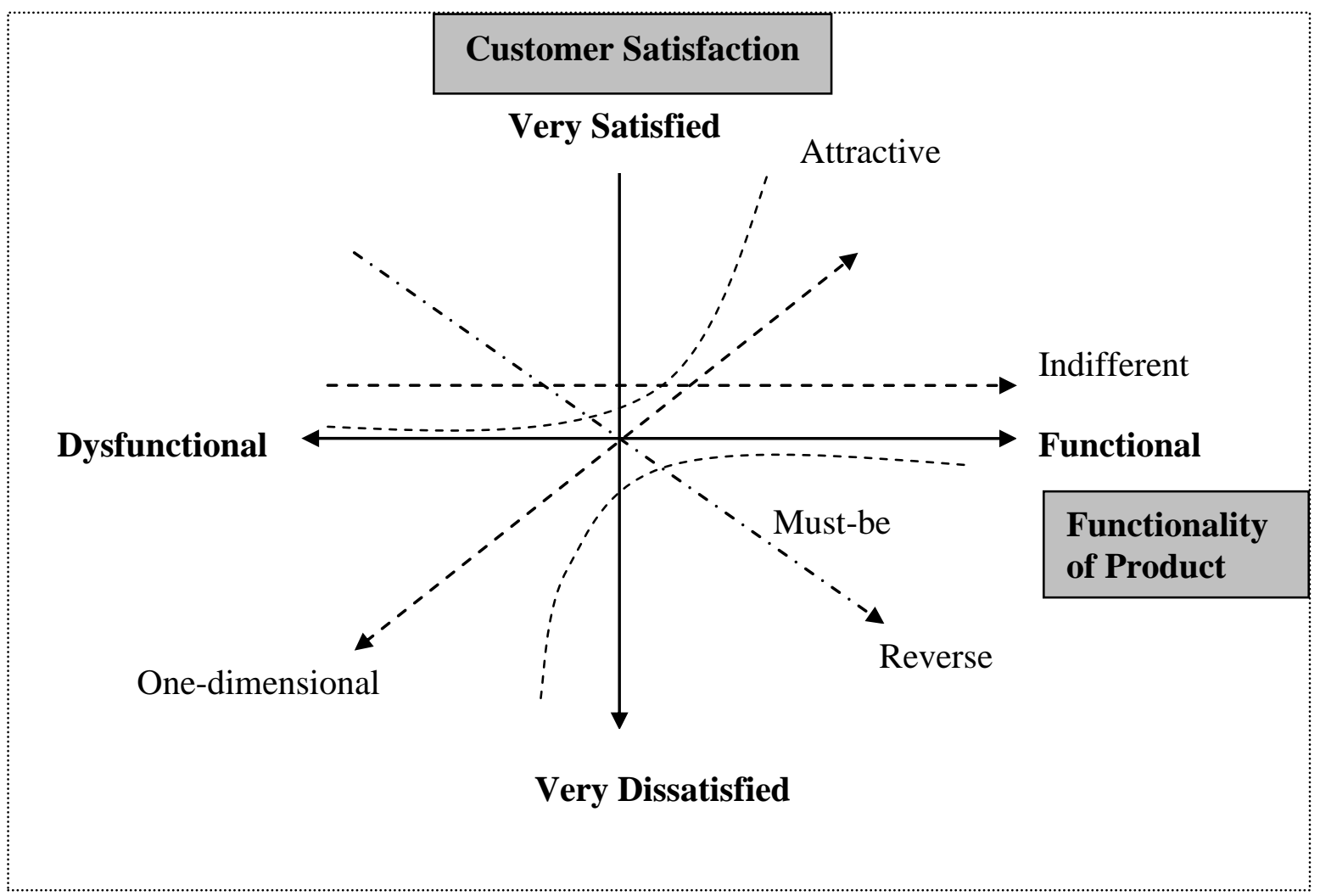

Figure 01: The Kano diagram

\section{Phase I - Identifying the Food Quality} Attributes of Milk Powder

As the first step towards use of KAM, based on the Caswell's classification on food quality, there were 18 intrinsic and extrinsic quality attributes $(j)$ pertaining to milk powder (i.e. $\mathrm{Q}=18$ ) listed along with their different "forms" (Table 1).

Once the preferable attributes of quality were defined (e.g. 18 attributes in this case), the following methods specified in the KAM were used to choose the "most preferred forms" of each attribute. First, the respondents were asked to "rank" the different forms of an attribute based on their preferences using $1,2,3 \ldots \mathrm{m}$ (where $\mathrm{m}=$ number of forms of an attribute) [i.e. the most preferable form $=1$, the second most preferable form $=2$ and so on up to the $\mathrm{m}^{\text {th }}$ form] for all attributes. For a given attribute, the form to which the most number of respondents in the sample given the rank 1 was selected as the most preferred form of that attribute subjected to the fact that more than $50 \%$ of respondents must select that particular attribute as their $1^{\text {st }}$ choice (e.g. assume that more than $50 \%$ of respondents choose 
"vanilla" form as the most preferred form for the "taste" attribute) ${ }^{2}$.

\section{Phase II: Use of KAM to Categorize Food Quality Attributes}

The aim of this phase was to classify the attributes of food quality in terms of categories shown in Kano analysis, where the "forms" of an attribute selected in Phase I were used. For this task, a special questionnaire called "Kano Questionnaire" should be prepared, which, together with any other information about the respondent, mainly consists of two types of questions as follows.

First, a set of questions equal to the number of attributes considered in the analysis (i.e. $\mathrm{Q}=18$ ) was prepared, in which each question should be comprised of two parts, namely: "Functional" and "Dysfunctional" forms of the attribute. The first question in each pair of questions for an attribute was referred to a situation in which the "requirement was met" (i.e. the functional form of question). In opposite, the dysfunctional form in each pair was referred to the case where the "requirement was not met" (Berger et al., 1993).As recommended in the KAM, the $1^{\text {st }}$ preferred form of an attribute (selected in Phase I) was considered as the functional form of the question, and the $3^{\text {rd }}$ preferred form was selected as the dysfunctional form of each question (leaving $2^{\text {nd }}$ choice to create a "gap"

\footnotetext{
${ }^{2}$ A problem arises if any of the forms specified for an attribute in concern is not chosen by more than $50 \%$ of the respondents as their $1^{\text {st }}$ choice. Under that circumstance, the cumulative percentage of $1^{\text {st }}$ and $2^{\text {nd }}$ choices given to each form of those attributes is to be considered in selecting the most preferred form. In case, if this too does not satisfy the $50 \%$ criterion for certain attributes, the cumulative percentage of the $1^{\text {st }}$, $2^{\text {nd }}$ and $3^{\text {rd }}$ choices given to the forms of those attributes is considered. An analyst experienced in the KAM, usually, "code" all the preferences (i.e. $1^{\text {st }}, 2^{\text {nd }}$ and $3^{\text {rd }}$ ) given by respondents to all forms of all attributes to start with this part of the analysis, and select the most, second most and third most preferable forms (and so on) of an attribute afterward using the resulting cumulative percentages.
}

between these consumer preferences). However, in the cases where a particular attribute possesses "binary" answers (e.g. Yes or No), the functional form is to be selected as the "positive" answer (i.e. consideration of attribute) and the "negative" answer automatically becomes the dysfunctional form (i.e. no consideration of attribute). A respondent was, in turn, supposed to provide an answer to each question using one of the five different ways as pointed out in Table 2.

Second, another set of questions was formulated (i.e. no. of questions $=$ no. of attributes $=18$ ) to explain extent to which each attribute considered in the analysis was important to a respondent (i.e. "selfstated importance questionnaire") (see, the example in Table 3). Each question was, in turn, rated by the respondents on a 9-point Likert-scale ranging from "not at all important $=1$ " to "extremely important $=$ 9".

The scores provided by respondents to these two different sets of questions were used to classify food quality attributes into the Kano categories by means of two distinct methods: (1) the Gaphical and Continuous Analysis (GCA), and (2) the Kano Evaluation Table (KET). As the outcome from the KET was analogous to GCA, this article in particular discusses about the results from the GCA. Below explains, in brief, the theoretical aspects related to development of a "Basic Plot" to conduct the GCA. 
Table 01: Food quality attributes of milk powder based on Caswell's classification:

\begin{tabular}{|c|c|c|}
\hline Attribute of Quality & Notation & Forms of the Attribute \\
\hline \multicolumn{3}{|l|}{ Food Safety } \\
\hline 1. Pathogens & PAT & Bacteria, Virus, Botulism, E-coli, \\
\hline 2. Food additives \& & FAP & Added to the food, Not added to the food \\
\hline \multicolumn{3}{|l|}{ Preservatives } \\
\hline \multicolumn{3}{|l|}{ Nutrition } \\
\hline 3. Fat \& Cholesterol & FCC & Full cream, Non fat, Malted \\
\hline 4. Calories & CAL & Low, Medium, High \\
\hline \multicolumn{3}{|l|}{ Sensory / Organoleptic } \\
\hline 5. Taste & TAS & $\begin{array}{l}\text { Vanilla, Chocolate, Strawberry, Malted, Other } \\
\text { flavor }\end{array}$ \\
\hline 6. Appearance & APP & Soft dry powder, Liquid, Cream, Small granules \\
\hline 7. Smell & SME & Vanilla, Chocolate, Without, Other \\
\hline \multicolumn{3}{|l|}{ Value / Functional } \\
\hline 8. Size & SIZ & $75 \mathrm{~g}, 250 \mathrm{~g}, 400 \mathrm{~g}, 500 \mathrm{~g}, 1 \mathrm{~kg}$ \\
\hline $\begin{array}{l}\text { 9. Compositional } \\
\text { Integrity }\end{array}$ & COI & Yes, No \\
\hline 10. Package Material & PAM & $\begin{array}{l}\text { Aluminum foil only, Aluminum foil with } \\
\text { cardboard packet, Tetra packet }\end{array}$ \\
\hline 11.Keepability (after opening) & KEE & 1 week, 1-3 week, 3-5 week, >5 Week \\
\hline \multicolumn{3}{|l|}{ Process } \\
\hline 12. Place of Origin & PLO & $\begin{array}{l}\text { Australia, New Zealand, India, Denmark, Sri } \\
\text { Lanka }\end{array}$ \\
\hline \multicolumn{3}{|l|}{ Text / Measurement } \\
\hline 13. Certification & CER & SLS, ISO 9001, HACCP, GMP \\
\hline 14. Labeling & LEB & Yes, No \\
\hline \multicolumn{3}{|l|}{ Cues } \\
\hline 15. Price & PRI & Rs. 50-100, Rs. $150-200$, Rs. $250-300,>$ Rs. 300 \\
\hline 16. Brand Name & BRN & $\begin{array}{l}\text { Anchor, Nespray, Lakspray, Red Cow, Highland, } \\
\text { Raththi, Kothmale }\end{array}$ \\
\hline 17. Advertising & $\mathrm{ADV}$ & Television, Radio, Newspapers, Others \\
\hline $\begin{array}{l}\text { 18. Past Purchase } \\
\text { Experiences }\end{array}$ & PPE & Yes, No \\
\hline
\end{tabular}

Table 02: Pair of question and the standard answers in the Kano questionnaire:

Functional Form

If the packaging material of milk powder is made of Aluminum foil with cardboard packet, how would you feel?
1. I like it that way.

2. It must be that way.

3. I am neutral.

4. I can live with it that way.

5. I dislike it that way.

1. I like it that way.

2. It must be that way.

3. I am neutral.

4. I can live with it that way.

5. I dislike it that way.

Dysfunctional Form 
Table 03: Scale of Self-stated Importance questionnaire:

\begin{tabular}{cccccccc}
$\begin{array}{l}\text { Not at all } \\
\text { Important }\end{array}$ & $\begin{array}{l}\text { Somewhat } \\
\text { Important }\end{array}$ & Important & $\begin{array}{c}\text { Very } \\
\text { Important }\end{array}$ & $\begin{array}{c}\text { Extremely } \\
\text { Important }\end{array}$ \\
\hline 1 & 2 & 3 & 4 & 5 & 6 & 7 & 8 \\
\hline
\end{tabular}

How important is it

or would it be if: the

milk powder has

packaging material?

The answers from $\mathrm{N}$ number of respondents $(\mathrm{i}=1,2,3 \ldots \mathrm{N})$ to $\mathrm{Q}$ number of questions $(\mathrm{j}=1,2,3 \ldots \mathrm{Q})$ in three different modes, i.e.: (a) functional; (b) dysfunctional, and (c) self-stated importance are coded as follows:

Functional: $\quad Y_{\mathrm{ij}}=-2$ (Dislike), -1 (Live with), 0 (Neutral), 2 (Must-be), 4 (Like)

Dysfunctional: $\mathrm{X}_{\mathrm{ij}}=-2$ (Dislike), -1 (Live with), 0 (Neutral), 2 (Must-be), 4 (Like)

Importance: $\quad \mathrm{W}_{\mathrm{ij}}=1$ (Not at all important)..., 9 (Extremely important)

The scores from all respondents for all attributes in three different modes ( $Y, X$ and $\mathrm{W}$ ) was used to derive the average score of each mode as follows:

$\mathrm{X}$ average $(\mathrm{j})=\Sigma_{\mathrm{i}} \mathrm{X}_{\mathrm{ij}} / \mathrm{N}$

$\mathrm{Y}$ average $(\mathrm{j})=\Sigma_{\mathrm{i}} \mathrm{Y}_{\mathrm{ij}} / \mathrm{N}$

$\mathrm{W}$ average $(\mathrm{j})=\Sigma_{\mathrm{i}} \mathrm{W}_{\mathrm{ij}} / \mathrm{N}$

The "Basic Plot", which is the square that $\mathrm{X}$ average and $\mathrm{Y}$ average range from 0 to 4 , is divided into 4 quadrants showing the categories of: "One-dimensional", "Attractive", "Must-be" and "Indifferent". The attributes of quality considered in the analysis were allocated to these quadrants based on the scores they obtained, and to find the relative position of attributes within a quadrant (i.e. degree of differentiation of importance level within the quadrant), the scores from "self-stated importance questions" was used.

\section{Data Collection and Analysis}

To collect the data in Phase 1, consumers were contacted $\left(\mathrm{N}^{1}=175\right)$ at three largescale supermarkets located in Welliweriya, Ganemulla and Kadawatha in the Gampaha District during May 2008. It was emphasized to select a nearly equal number of male and female respondents to the sample to make the outcome of analysis gender neutral. Only those consumers who indicated that they were used to purchase and consume at least 2 packets of $400 \mathrm{~g}$ (or 1 packet of $700 \mathrm{~g}$ ) per month from one of five market leading milk powder brands from a supermarket setting were elected for collection of data, because it helps to make the sample homogenous in terms of consumers' lifestyle and purchasing patterns. The same criteria were adopted in selecting the respondents for the Phase II $\left(\mathrm{N}^{2}=150\right)$, where the data collection was carried out at the same supermarkets during June 
2008. The KAM explained above were adopted with the data and the results are reported, in turn.

\section{RESULTS AND DISCUSSION}

\section{Descriptive Statistics of the Sample}

The socio-economic characteristics of consumers participated to the study in both
Phase I and II are summarized in Table 4.It highlights that the age of majority of respondents were less than 40 years and educated up to the secondary level (i.e. Advanced Level). The characteristics of sample infer that the preferences revealed in the analysis were, in general, gender neutral and consumers have answered the questions with some good understanding about attributes of product quality.

Table 04: Descriptive statistics of sample in the Phase 1 and Phase II

\begin{tabular}{llllll}
\hline \multicolumn{2}{c}{ Demographic Character } & \multicolumn{2}{c}{$\begin{array}{c}\text { Phase I } \\
(\mathbf{N = 1 7 5})\end{array}$} & \multicolumn{2}{c}{$\begin{array}{c}\text { Phase II } \\
\text { (N=150) }\end{array}$} \\
Character & Categories & No & \% & No & \% \\
\hline Age & $>$ 40 years & 123 & 71.5 & 115 & 76.7 \\
\multirow{3}{*}{ Gender } & $<40$ years & 47 & 28.5 & 35 & 24.3 \\
& Male & 85 & 49.4 & 69 & 46.0 \\
\multirow{2}{*}{ Level of } & Female & 87 & 51.6 & 81 & 54.0 \\
Education & Primary & 63 & 36.0 & 44 & 29.3 \\
& Secondary & 90 & 52.0 & 84 & 56.6 \\
& Tertiary & 19 & 11.1 & 22 & 14.1 \\
\hline
\end{tabular}

Different Forms of Attributes Identified in Phase I

The $1^{\text {st }}, 2^{\text {nd }}$ and $3^{\text {rd }}$ most preferred forms of attributes $(\mathrm{Q}=18)$ and the direct (i.e. passed $50 \%$ criterion with the $1^{\text {st }}$ choice) or cumulative percentage (i.e. cases where the analysis has been extended to count the $2^{\text {nd }}$ and $3^{\text {rd }}$ choices to pass the $50 \%$ criterion) these forms obtained were reported in Table 5.It shows that for only 7 out of 18 attributes considered in the analysis (i.e. Calories, Appearance, Package material, Keepability, Certification, Brand name and Advertising) satisfied the $50 \%$ criterion under the $1^{\text {st }}$ choice. For all other attributes, the $2^{\text {nd }}$ or the $3^{\text {rd }}$ choices were taken into account. Figure 2 shows the outcome of analysis for the taste attribute for an illustrative purpose.It shows that none of the forms of the taste attribute considered in the analysis satisfied the $50 \%$ criterion with the $1^{\text {st }}$ choice. The highest value calculated was $45.9 \%$ for the vanilla form. As a result, the $2^{\text {nd }}$ choice was taken into account with each form. With the $2^{\text {nd }}$ choice, the cumulative percentage of Vanilla and Chocolate forms was above $50 \%$. The Vanilla flavor $(79.1 \%)$ was, therefore, selected as the $1^{\text {st }}$ preferred form and Chocolate flavor $(77.9 \%)$ was selected as the $2^{\text {nd }}$ preferred form. Since any other forms categorized under the flavor attribute did not pass the $50 \%$ criterion, the $3^{\text {rd }}$ choice was taken into account. The Molted flavor was selected as the $3^{\text {rd }}$ preferred form of flavor attribute as its value was greater than $50 \%$ (i.e. $70.3 \%$ ) with the $3^{\text {rd }}$ choice. Consequently, the Vanilla and Molted forms were selected as the Functional and Dysfunctional forms, respectively, in the Kano questionnaire. 
Table 05: Consumer consideration on various forms of quality attributes

\begin{tabular}{|c|c|c|c|}
\hline Attribute of Quality & The Most Preferred & $2^{\text {nd }}$ Most Preferred & $3^{\text {rd }}$ Most Preferred \\
\hline \multicolumn{4}{|l|}{ Food Safety } \\
\hline 1. Pathogen & Bacteria $(79.7)^{* *}$ & Virus $(66.9)^{* *}$ & Botulism $(58.8)^{* * *}$ \\
\hline 2. Food additives \& & Added $(52.3)^{*}$ & & Not Added (47.7) \\
\hline \multirow{2}{*}{\multicolumn{4}{|c|}{ Nutrition }} \\
\hline & & & \\
\hline 3. Fat \& Cholesterol & Full cream $(82.6)^{* *}$ & Non fat $(74.4)^{* * *}$ & Malted (48.9) ${ }^{* * *}$ \\
\hline 4. Calories & Medium $(74.4)^{*}$ & $\operatorname{High}(66.2)^{* * *}$ & Low $(98.3)^{* * * *}$ \\
\hline \multicolumn{4}{|l|}{ Sensory / Organoleptic } \\
\hline 5. Taste & Vanilla $(79.1)^{* *}$ & Chocolate $(77.9)^{* *}$ & Molted $(70.3)^{* * *}$ \\
\hline 6. Appearance & Soft dry powder $(68.6)^{*}$ & $\begin{array}{l}\text { Cream } \\
(83.7)^{* *}\end{array}$ & Small granules $(52.3)^{* *}$ \\
\hline 7. Smell & Vanilla $(83.7)^{* *}$ & Chocolate $(59.8)^{* *}$ & Without $(52.3)^{* *}$ \\
\hline \multicolumn{4}{|l|}{ Value / Functional } \\
\hline 8. Size & $400 \mathrm{~g}(73.2)^{* *}$ & $250 \mathrm{~g}(62.2)^{* *}$ & $500 \mathrm{~g}(66.3)^{* * *}$ \\
\hline $\begin{array}{l}\text { 9. Compositional } \\
\text { Integrity }\end{array}$ & Yes $(62.2)^{*}$ & & No $(37.8)^{*}$ \\
\hline 10. Package Material & $\begin{array}{l}\text { Al foil with cardboard } \\
\text { packet }(58.1)^{*}\end{array}$ & $\begin{array}{l}\text { Aluminum foil only } \\
(83.1)^{* *}\end{array}$ & Tetra packet $(92.4)^{* * *}$ \\
\hline 11. Keepability & 1 week $(55.8)^{*}$ & $1-3$ week $(94.8)^{* *}$ & 3-5 week $(95.9)^{* * *}$ \\
\hline \multicolumn{4}{|l|}{ Process } \\
\hline 12. Place of Origin & $\begin{array}{l}\text { New Zealand } \\
(94.8)^{* * *}\end{array}$ & $\begin{array}{l}\text { Australia } \\
(76.2)^{* * *}\end{array}$ & Denmark $(68.1)^{* * * *}$ \\
\hline \multicolumn{4}{|l|}{$\begin{array}{l}\text { Text / Measurement } \\
\text { indicators }\end{array}$} \\
\hline 13. Certification & ISO $9001(48.2)^{*}$ & $\operatorname{SLS}(85.5)^{* *}$ & $\operatorname{HACCP}(84.9)^{* * *}$ \\
\hline 14. Labeling & Yes $(87.2)^{*}$ & & No $(12.8)^{*}$ \\
\hline \multicolumn{4}{|l|}{ Cues } \\
\hline 15. Price & $150-200(86.0)^{* *}$ & $250-300(59.8)^{* *}$ & $50-100(64.5)^{* * *}$ \\
\hline 16. Brand Name & Anchor (51.2) & Nespray $(63.9)^{* * *}$ & Lakspray $(56.4)^{* * * *}$ \\
\hline 17. Advertising & Television $(76.2)^{*}$ & Radio $(50.0)^{* *}$ & Newspaper $(48.3)^{* *}$ \\
\hline $\begin{array}{l}\text { 18. Past Purchase } \\
\text { Experiences }\end{array}$ & Yes $(95.3)^{*}$ & & No $(4.7)^{*}$ \\
\hline
\end{tabular}

\section{Classification of Food Quality Attributes into Kano Categories}

Figure 3 illustrates the "Basic Plot" of GCA, which categorizes the food quality attributes considered in the analysis into four Kano categories. It shows that 4 attributes, namely: calorie content (CAL), compositional integrity (COI), labeling (LEB) and past purchase experiences (PPE) had fallen into the upper-right quadrant of the basic plot by suggesting that consumers, in general, perceive those attributes as "One-dimensional." 


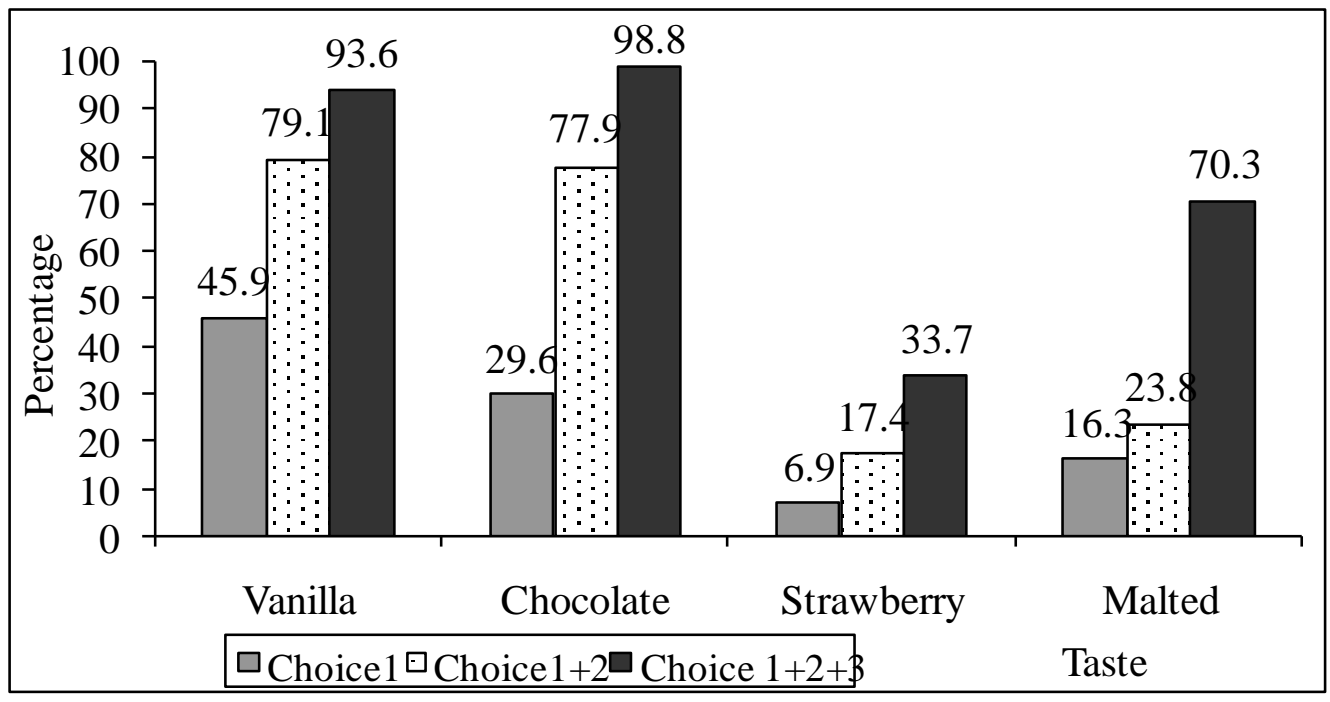

Figure 02: Most preferred forms of Taste attribute

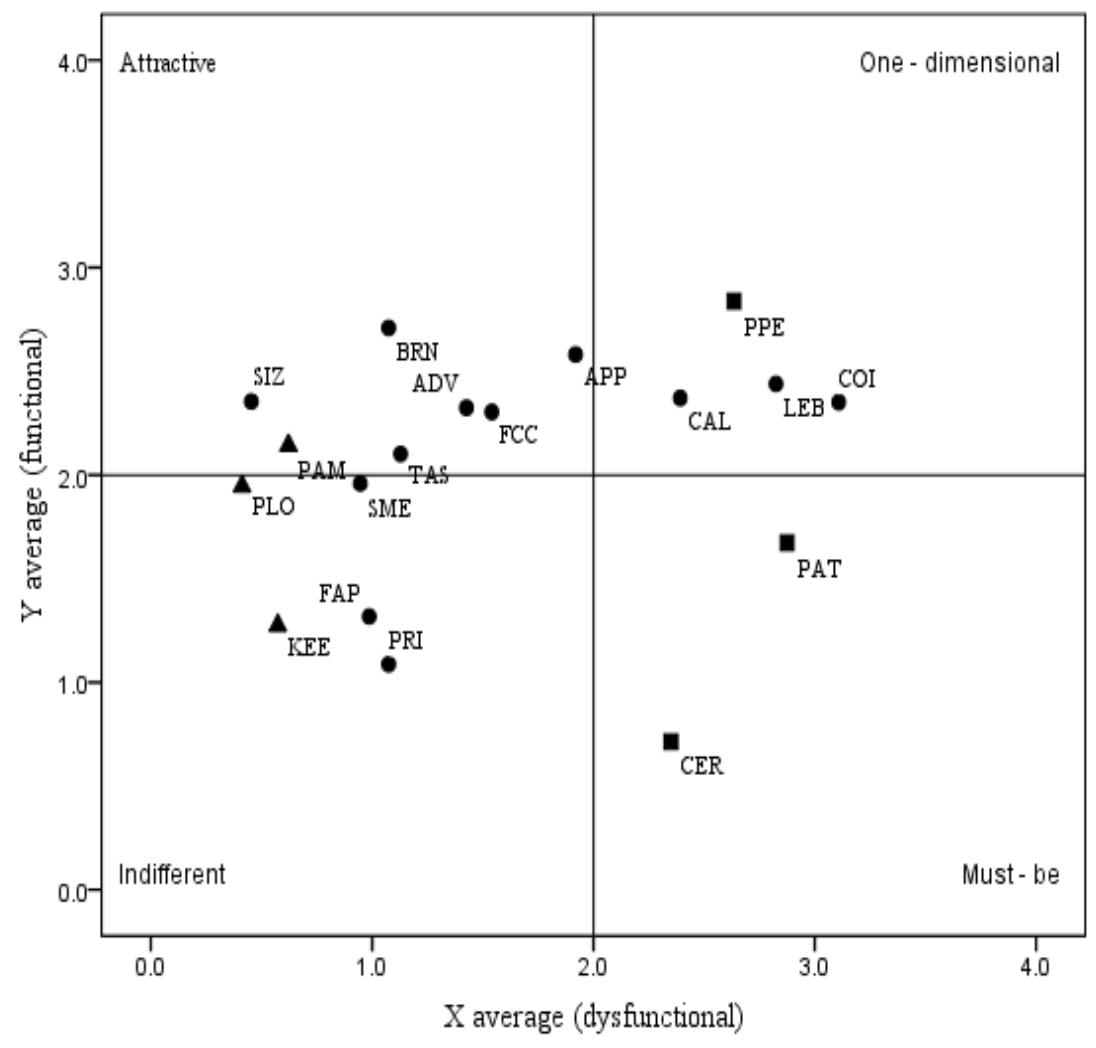

Average Importance

Intervals:

$4.0-5.0 \triangle 5.1-6.0$

$6.1-7.0 \square$

Figure 03: The "Basic Plot" of graphical and continuous analysis 
Interestingly, these 4 attributes represent four different subsets in the Caswell's classification, i.e. CAL from nutrition, COI from value, LEB from text/measurement and PPE from cues. This indicates that consumers would be happy as the level of these attributes increases. Given that CAL and COI were categorized under the intrinsic quality indicators in the Caswell's classification, the producers may take extra precautions in their efforts to increase the nutrition level and compositional integrity to attract consumers. The results show that consumers have rated both LEB and PPE (extrinsic quality indicators) high (i.e. 6 7) on the 9-point Likert scale that these attributes were evaluated. The reason behind this 'high importance' for these two attributes may be that a consumer can easily make his/her decision to purchase milk powder when the label of the product is complete and more descriptive and as he/she gets more experienced, or in other words, he/she is familiar with the information environment ("search" and/or "experience" characteristics).

Other 7 attributes, namely: brand name (BRN), advertising (ADV), fat and cholesterol content (FCC), taste (TAS), size (SIZ), appearance (APP) and package material (PAM) were classified as "Attractive" attributes. Except BRN and ADV, the other 5 attractive attributes were considered as intrinsic food quality attributes in the Caswell's classification. The TAS and FCC are considered as having "experience" and "credence" characteristics, respectively, with respect to information environment, while the rest are showing "search" characteristics. Interestingly, PAM has a relatively low (4 - 5) importance level amongst the 4 attractive attributes with search characteristic. The results highlight that producers can play a major role to expand the sales of their products by make it to size that fits into consumers' needs and purchasing power, increasing the appearance of package material, wellplanned advertizing program and promotion of the brand name. At the same time, products with less fat and no or minimal amount of cholesterol is becoming more attractive.

Another 3 attributes, namely: food additives \& preservatives (FAP), price (PRI) and keepability (KEP) were to a greater extent and other 2 attributes, namely: place of origin (PLO) and smell (SME) were just fallen into the bottom-left quadrant, which demonstrates the "Indifferent" characters. This suggests that consumers loyal to a supermarket setting were relatively price insensitive and did not bother about whether the product is contaminated with unhealthy food additives and preservatives as they decide on purchasing milk powder. Consumer loyalty to a particular milk powder brand/s with possesses dependable product quality characteristics and relatively fixed price may be the reasons for such a behavior. The results highlight that with a little effort the other attributes can be made attractive for consumers, i.e. by exposing the country of origin of the product where the consumers, in general, are confused and enhancing the smell as these attributes were placed in the border of the indifference quadrant.

The remaining 2 attributes, namely: pathogens in food (PAT) and certification (CER) were considered as having "Must$b e$ " characteristics. This is a clear indication that consumers prefer to have product completely free from harmful pathogens, or in other words, food safety is a serious matter. Also, they believe that milk powder products must be subjected to an accredited certification system like Hazard Analysis and Critical Control Points (HACCP) and/or Good Manufacturing Practices (GMP). 


\section{CONCLUSIONS}

In the modern world, it is claimed that customer demand for quality of food product has increased in relation to that for quantity, especially for the products that are sensitive and possesses a large number of substitutes and consumers are rich enough to exercise their choices in the marketplace. This study examined this phenomenon for the special case of purchasing of milk powder from a supermarket setting, where the consumer consideration and level of importance towards the quality attributes include in the subsets of the Caswell's classification were considered The results of the analysis were based on the graphical and continuous method of Kano analysis parallel with the self-stated importance levels.

It reveals that consumers consider that absence of pathogens and accredited food certification as "Must-be" characteristics. Together with those, any improvement to a number of other attributes, for example the calorie content, past purchases experience, labeling and compositional integrity increase the consumer concern towards that particular product. Several other attributes, including packaging material, size and appearance; advertising, brand name, flavor and fat and cholesterol content can create any milk powder variety an attractive product for consumers.

The results suggest that the responsibility of securing the quality of milk powder products is laid mostly in the hands of producers and processors as the consumer are faced with a Monopolistically Competitive Market for this product where a consumer possesses the "freedom and choice" of substituting a one product with another if they judge that the former is not in par with their wishes with respect to these attributes of quality. The outcome of this sort of analysis can help food producers immensely to judge on what aspects consumers value their products, and in turn, to response to those quality attributes. However, care must be taken as the results can be changed from characteristics of the consumer as well as the market setting.

\section{ACKNOWLEDGMENT}

The authors wish to express their gratitude to the Management of the "Salinda Super Market" chain and all the respondents to the questionnaire-based survey.

\section{References}

Berger, C., R. Blauth, D. Boger, C.Bolster, D. Burchill, W. Du-Mouchel, F. Pouliot, R.Richter, A.Rubinoff, D.Sken, M.Tinko and D.Walden. (1993). Kano's methods for understanding customer-defined quality. Journal of Center for Quality Management. 2 (4), pp: 3 - 28.

Buzby, J. C., P. D. Frenzen, and B. Rasco. (2001). Product liability and microbial food borne illness. Agricultural Economic Report - No. 799. Economic Research Service, United States Department of Agriculture.

Buzby, J. C. (2003). International trade and food safety: economic theory and case studies. Agricultural Economic Report - No. 828. Economic Research Service, United States Department of Agriculture.

Brown, G. H. (1994). Measuring consumer attitudes towards products. Journal of Marketing 14 (5), pp: 691 - 98. 
Caswell, J. A., C. M. Noelke, and E. M. Mojduszka, (2000). Frameworks for analyzing quality and quality assurance for food products. Global Food Trade and Consumer Demand for Quality, pp: 43 - 62.

Caswell, J. A. (1998). Valuing the benefits and costs of improved food safety and nutrition. Australian Journal of Agriculture and Resource Economics 42 (December), pp: 409 474.

Caswell, J. A. and E. M. Mojduszka, (1996). Using informational labeling to influence the market for quality in food products. American Journal of Agricultural Economics 78(5), pp: 1248 - 1253.

Caswell, J. A. and D.Padberg (1992). Towards a more comprehensive theory of food labels. American Journal of Agricultural Economics 74(2), pp: 460 - 468.

Espejel, J., C. Fandos and C.Favian. (2007). The role of intrinsic and extrinsic quality attributes on consumer behavior for traditional food product. Journal of Managing Service Quality. 17 (6), pp:681-701.

Garvin, D. A. (1987). Competing on the eight dimensions of quality. Harvard Business Review 65(6),pp: $101-109$.

Henson, S. and J.Caswell. (1999). Food safety regulation: an overview of contemporary issues. Food Policy 24,pp: 589 - 603

Hooker, N. H., and J. A. Caswell. (1998). Trends in food quality regulation: implications for processed food trade and foreign direct investment. Agribusiness 12(5),pp: 411 - 419.

Jayasinghe-Mudalige, U. K. and S.Henson. (2006), Economic incentives for firms to implement enhanced food safety controls: case of the Canadian red meat and poultry processing sector. Review of Agricultural Economics 28(4),pp: 494 - 514.

Kano, N., N. Seraku, F. Takahashi and S. Tsjui. (1984). Attractive quality and must-be quality. Hinshitsu 14(2),pp: 147 - 156.

Spriggs, J. and G.Isaac. (2001). Food Safety and International Competitiveness: The Case of Beef. CABI Publishing. Oxon. United Kingdom.

Zhifeng, G. (2007). Effects of additional quality attributes on consumer willingness-to-pay for food products. Department of Agricultural Economics, Kansas State University of USA. Available from: http: //ageconsearch. umn.edu/bi tstream /9900/1/sp07ga02.pdf (Accessed 09 June 2008). 